\title{
Parametric Investigation of EP To Enhance Surface Characteristics of Maraging Steel With Organic Electrolyte
}

\author{
Abhinav Kumar \\ Indian Institute of Technology Guwahati \\ Suraj Kumar \\ Indian Institute of Technology Guwahati \\ Manas Das ( $\square$ manasdas@iitg.ernet.in ) \\ IIT Guwahati
}

\section{Research Article}

Keywords: Maraging steel, Electropolishing, Surface roughness, Surface reflectance, Contact angle

Posted Date: November 8th, 2021

DOI: https://doi.org/10.21203/rs.3.rs-932299/v1

License: (c) (i) This work is licensed under a Creative Commons Attribution 4.0 International License.

Read Full License 


\section{Abstract}

Maraging steel 300 is widely used in aircraft, tools, and automotive industries, which requires a polished surface for better performance. In conventional methods of polishing, the abrasives directly contact the workpiece surface and deteriorate its property. Thus, a non-conventional method like Electropolishing (EP), is utilized to finish maraging steel with acetic acid (99.7 wt.\%) and perchloric acid (70 wt.\%) mixed in the volume of 3:1. Linear sweep voltammetry (LSV) is performed to determine the passive region that gives the best electropolishing performance. Different parameters, namely temperature, agitation, and polishing time and their effect on surface roughness and surface reflectance, are observed during EP. The optimized process parameters which give the best EP performance are the temperature at $60^{\circ} \mathrm{C}$, rotation of magnetic stirrer at $400 \mathrm{rpm}$, and polishing time of 6 minutes. An improvement of $56 \%$ in surface roughness and $60 \%$ in surface reflectance from its initial value of $21 \%$ is observed. EP makes the surface hydrophilic as the contact angle changes from $111.2^{\circ}$ to $68.6^{\circ}$. Energy-Dispersive X-Ray Spectroscopy analysis suggests that after EP, a metal oxide layer forms on the surface which helps in increasing corrosion resistance.

\section{Introduction}

Electropolishing (EP) is a non-conventional polishing method that follows anodic dissolution. The polishing setup comprises of an anode (sample to be electropolished), a cathode (tool), and an electrolyte. In EP, the electrolyte in mainly consists of viscous acidic fluid. During EP, the hydrogen gas is evolved at the tool and oxygen gas at the workpiece followed by anodic dissolution, as shown in Fig. 1. Due to the diffusive mechanism in EP, as explained by Jacquet's viscous film theory [1], a viscous film forms over the workpiece surface. This viscous layer increases electrical resistance for anodic dissolution. A thick layer forms on the valley, whereas a thin layer forms on the anode's protruding surface. Due to this difference in the layer thickness, a higher resistance for anodic dissolution for valleys than protruding surfaces is observed. This creates a polishing effect by removing the protruding surface first, followed by the valley. Hence, the surface is leveled and polished during EP [2]. It does not change the actual property of the bulk metal and also forms a stable passive oxide layer which increases the corrosion resistance [3].

During electropolishing, oxygen gas evolves at anode forming bubbles and moves away the electropolishing solution from the anode film surface. Hence, the protruding surface on the workpiece dissolves faster, while the valley remains inaccessible [4]. EP does not change the crystallographic and grain-boundary structure of the bulk material and never induces any residual stress, which makes it different from other polishing methods [5]. This advantage of EP is utilized as a post-processing method for components fabricated by thermal-induced processes like laser beam machining (LBM), Electric discharge machining (EDM), etc.

This paper performs EP of maraging steels as it offers competitive alternative materials for aerospace structures while exhibiting ultra-high-strength and good corrosion resistance [6]. It is widely used as raw 
powders in additive manufacturing to fabricate complex parts [7].

Oliveira et al. [8] used the powder bed fusion process for 3D printing of maraging steel 300 . The effects of cutting parameters like feed per tooth and cutting speeds on the surface conditions, namely average roughness and residual stress during milling, were investigated. Surface roughness of $3.30 \mu \mathrm{m}$ was obtained after additive manufacturing. Milling was used as a post-processing technique to reduce the surface roughness to $0.31 \mu \mathrm{m}$ at $250 \mathrm{~m} / \mathrm{min}$ cutting speeds and $0.02 \mathrm{~mm} /$ tooth feed per tooth. Compared to EP, the conventional milling process directly contacts the workpiece, changes workpiece's grain structure completely, and induces compressive residual stress.

Li et al. [9] polished maraging steel by micro-grinding and achieved a minimum roughness of $0.67 \mu \mathrm{m}$. They found that while polishing at a very high speed, the metal surface property changes drastically. They proposed a small grinding wheel with a very low rotating speed to avoid this. Also, residual stress was induced on the workpiece surface while polishing by micro-grinding [9]. These disadvantages of conventional polishing methods make way for researchers to proceed in non-conventional polishing methods.

Very few literatures are found for the electropolishing of maraging steel. As it is a Ni-based alloy, the author tries to find the electrolyte for the electropolishing of Ni-based alloys. Huang et al. [10] had utilized perchloric-acetic mixed acids electrolyte to investigate the EP behavior of Inconel 718 alloy. Anodic polarization curves at different concentrations of perchloric acid $\left(\mathrm{HClO}_{4}\right)$ were analyzed, and it was concluded that more than 50 vol.\% of $\mathrm{HClO}_{4}$ provides better anodic dissolution. EP enhances the corrosion resistance of Inconel 718 alloy. For Ni-based alloys, perchloric-acetic acid mixtures are generally used as an electrolyte [10]-[12]. Aksu et al. [12] had electropolished Fe-Ni-Co alloy in perchloric acid solution with acetic acid as a solvent. Linear sweep voltammetry was performed to find the current density for different concentrations of perchloric acid. An investigation was conducted to analyze the effect of electrolyte concentration, current density, and bath temperature on surface roughness and thickness change. Surface roughness of $0.05 \mu \mathrm{m}$ is achieved.

Wang et al. [13] had investigated the parameters of electropolishing on the surface quality of Ni-Ti shape memory alloy after milling. It was observed that better the initial surface homogeneity, better would be EP effect. Methanol-perchloric acid mixture was used as an electrolyte to achieve a minimum roughness of $0.279 \mu \mathrm{m}$. Han and Fang [14] had compared $\mathrm{NaCl}$-based electrolyte with $\mathrm{H}_{2} \mathrm{SO}_{4}$-based electrolyte for EP of stainless steel 316L. It was observed that the $\mathrm{NaCl}$-based electrolyte has a higher current density, which leads to a higher material removal rate. Surface roughness of $20.4 \mathrm{~nm}$ and $100 \mathrm{~nm}$ had been achieved for the respective electrolytes.

In the present study, electropolishing of maraging steel is performed. An organic electrolyte solution containing acetic acid with perchloric acid is used for electropolishing. The various parameters like polishing time, temperature, and agitation are analyzed. Linear sweep voltammetry (LSV) is performed to generate the polarization curve for maraging steel at a particular solution. Energy-Dispersive X-Ray 
Spectroscopy (EDS) analysis is performed to investigate the workpiece surface composition before and after EP. The influence of EP parameters on surface roughness as well as surface reflectance is also presented. The contact angle of the surface is measured with the help of a goniometer to analyze the workpiece surface's wettability before and after EP. Corrosion behavior of the sample before and after EP is also studied.

\section{Electropolishing Experimental Procedure 2.1 Experimental Setup}

The schematic of the proposed electropolishing setup for maraging steel electropolishing is shown in Fig. 1. It is an extended version of the electrochemical machining (ECM) setup. It also contains an electrolyte circulation system and an arrangement for cathode and anode electrodes holding system. A glass container of $100 \mathrm{ml}$ is used as a chamber for electropolishing. A graphite sheet connected to the power supply's negative terminal is used as a cathode. The cathode is dipped inside the glass electrolyte chamber. A rectangular maraging steel 300 sheet of dimension $25 \mathrm{~mm} \times 10 \mathrm{~mm} \times 3 \mathrm{~mm}$ is used as the anode, which connects to the power supply's positive terminal. The complete setup is kept over a hot plate with the magnetic stirrer. The hot plate is used to provide the required amount of heat to increase electrolyte's temperature. The magnetic bar rotates within the glass chamber with the help of a magnetic stirrer. It agitates the solution during electropolishing. Hence, the dissolved particles are easily cleaned off from the workpiece the surface [14]. A DC power supply of $60 \mathrm{~V}$ and $20 \mathrm{~A}$ rating provides a potential difference between anode and cathode. The actual electropolishing experimental setup is shown in Fig. 2 . Table 1 shows the EP process parameters selected for polishing maraging steel. The major influencing parameters are electrolyte temperature, rotation of magnetic stirrer, and polishing time.

Table 1

Electropolishing process parameters

\begin{tabular}{|ll|}
\hline Parameters & Value \\
\hline Voltage & $6 \mathrm{~V}$ \\
\hline Electrolyte & Vol. ratio of acetic acid and Perchloric acid is $3: 1$ \\
\hline Polishing time & $4-10 \mathrm{~min}$ \\
\hline Agitation & $0-600 \mathrm{rpm}$ \\
\hline Temperature & $30-75^{\circ} \mathrm{C}$ \\
\hline
\end{tabular}

The flow chart, as shown in Fig. 3, describes step by step process of electropolishing. The first step is the preparation of the sample. The maraging steel is cut by wire-EDM and then mechanically polished consecutively with sandpapers of grit nos: 120,400 , and 600 for eliminating scratch marks and deformed layers from the test samples. The surface is manually cleaned using acetone. Further cleaning is 
conducted with deionized water in an ultrasonic cleaner for 15 minutes. The initial surface roughness $\left(\mathrm{R}_{\mathrm{a}}\right)$ of the specimen is about $0.27 \mu \mathrm{m}$.

\subsection{Electrochemical analysis}

A polarization curve is drawn utilizing linear sweep voltammetry (LSV) to correlate voltage and current for electropolishing. The organic electrolyte, which consists of acetic acid (99.7 wt.\%) and perchloric acid (70 wt.\%), are mixed in a volume ratio of 3:1. LSV provides three different zones such as active, passive, and transpassive. An electrochemical workstation (Gamry Instruments) with a three-electrode system, namely working electrode (maraging steel sample), counter electrode (platinum electrode), and reference electrode (Ag/ $\mathrm{AgCl}$ electrode), is used for LSV. The voltage is swept between 10 to $0 \mathrm{~V}$ with a scan rate of $10 \mathrm{mV} / \mathrm{s}$ [15]. The potential must be swept in the cathodic direction to avoid any pitting of the electrode surface while achieving reproducible measurements [16].

\subsection{Analysis of polished surface}

The polished surface morphology was analyzed with the help of an optical microscope. The sample is fixed in the epoxy resin using cold-setting to obtain the grain structure. The specimens were first mechanically polished with sandpapers of grit nos. 120,400, and 600 to eliminate the test samples' scratch marks and deformed layer. Finally, it is polished in buff cloth with $1 \mu \mathrm{m}$ diamond paste. For visualizing the micro-structure, the sample should be etched. A modified fry reagent consisting of $75 \mathrm{ml}$ of deionized water (DI), $25 \mathrm{ml}$ of hydrochloric acid (36 wt.\%), $12.5 \mathrm{ml}$ of nitric acid (68 wt.\%), and $0.5 \mathrm{~g}$ of copper (II) chloride $\left(\mathrm{CuCl}_{2}\right)$ is prepared as the etchant. For the etching of the cold mounted sample, the surface is scrubbed for approximately 60s with cotton, which is dipped in the solution, and then the surface is cleaned with deionized water and ethanol, followed by hot, dry air [17]. The metallographic structure is inspected with the help of a metallographic optical microscope.

The surface roughness $\left(R_{a}\right)$ was measured with the help of a non-contact optical profilometer. The surface area over which $\mathrm{R}_{\mathrm{a}}$ measured is $851 \mu \mathrm{m} \times 851 \mu \mathrm{m}$. An average of three surface roughness readings at different positions is calculated for the electropolished surface to get high reliability. The elemental composition is characterized with the help of Energy-dispersive X-ray spectroscopy (EDS).

Further, the contact angle is measured for the wettability study, i.e., hydrophilicity and hydrophobicity of the polished surface. It is inspected using a goniometer utilizing the sessile method of contact angle measurement. For this purpose, a water drop of $2 \mu \mathrm{l}$ is placed over the workpiece surface before and after EP [18]. The contact angle can be utilized to calculate the surface energy of the metallic workpiece surface [19]. An angle greater than $90^{\circ}$ signifies that the surface is hydrophobic, and an angle lesser than $90^{\circ}$ signifies hydrophilic.

Corrosion analysis is performed by utilizing the Tafel polarization curve by conducting experiments in potentiostat. The potential is varied from $-250 \mathrm{mV}$ to $+250 \mathrm{mV}$ vs. Ag/ AgCl with respect to the corrosion potential at a scan rate of $10 \mathrm{mVs}^{-1}$ using $3.5 \mathrm{wt}$ \% $\mathrm{NaCl}$ solution [20]. Various parameters like corrosion 
potential $\left(\mathrm{E}_{\text {corr }}\right)$ and corrosion current density $\left(\mathrm{I}_{\text {corr }}\right)$ are evaluated from the experimental curve. Table 2 shows all the operating conditions utilized during various operations performed to analyze the electropolished surface.

Table 2

Operating conditions

\begin{tabular}{|ll|}
\hline Experiments & Value \\
\hline Linear sweep voltammetry & Potential range: $10 \mathrm{~V}$ to $0 \mathrm{~V}$; Scan rate: $10 \mathrm{mV} / \mathrm{s}$ \\
\hline Surface reflectance & UV light with wavelength between 200 to $1000 \mathrm{~nm}$ \\
\hline Contact angle & Waterdrop of $2 \mu \mathrm{l}$ \\
\hline Tafel polarization & Potential range: $-250 \mathrm{mV}$ to $+250 \mathrm{mV}$; Scan rate: $10 \mathrm{mV} / \mathrm{s}$ \\
Electrolyte for corrosion & $3.5 \mathrm{wt} . \% \mathrm{NaCl}$ solution \\
analysis & \\
\hline
\end{tabular}

\section{Results And Discussions}

Electropolishing (EP) is performed on the maraging steel 300 sheet. The organic electrolyte consisting of acetic acid (99.7 wt.\%) and perchloric acid (70 wt.\%) is mixed in a volume ratio of 3:1. The setup for EP is indigenously designed and fabricated. It consists of electrolytes with electrodes. The effect of different parameters such as polishing time, temperature, agitation on surface roughness, and surface reflectance are investigated. The results are discussed in the following sub-sections.

\subsection{Anodic polarization behavior of maraging steel}

Linear sweep voltammetry (LSV) is performed to determine the anodic polarization behavior of maraging steel, as shown in Fig. 4. Three electrodes system is used to select the region of EP. The polarization curve is conducted by varying the potential from 10 to $0 \mathrm{~V}$ with a scan rate of $10 \mathrm{mV} / \mathrm{s}$. The polarization curve obtained in acetic acid (99.7 wt.\%) and perchloric acid (70 wt.\%) solution in maraging steel consists of three regions (Fig. 4). The region between 3 to $4 \mathrm{~V}$ is the active region (I) in which current increases with increased potential. The corresponding potential of $3 \mathrm{~V}$ is termed as activation potential $\left(\mathrm{E}_{\mathrm{a}}\right)$. The region between 4 to $6.2 \mathrm{~V}$ is the passive region (II), where the current is stable for an increase in voltage. The corresponding potential of $4 \mathrm{~V}$ is termed passivation potential $\left(E_{p}\right)$. After this region, the current increases rapidly in the transpassive region (III). The corresponding potential of $6.2 \mathrm{~V}$ is termed as breakdown potential $\left(E_{b}\right)$. As per literature, EP occurs only in the passive region. A viscous film having higher resistance than the electrolyte is formed in the passive region. Region (III) is also termed as gas evolution region where oxygen gas-bubbles are evolved. The reactions that take place during EP are discussed below in Eqs. (1) to (4) [14].

$M \rightarrow M^{n+}+n e^{-}$(at workpiece surface) (1) 
$n \mathrm{H}_{2} \mathrm{O}+n e^{-} \rightarrow \frac{n}{2} \mathrm{H}_{2}+n \mathrm{OH}^{-}$(at tool surface) (2)

$M^{+n}+n O H^{-} \rightarrow M(O H)_{n}$ (Near anode surface towards bulk electrolyte) (3)

$\mathrm{M}+\mathrm{nH}_{2} \mathrm{O} \rightarrow \mathrm{M}(\mathrm{OH})_{n}+\frac{n}{2} \mathrm{H}_{2}$ (Net process reaction) (4)

\subsection{Effect of electropolishing on elemental composition of surface}

Energy-Dispersive X-Ray Spectroscopy analysis is performed to investigate the elemental composition of maraging steel 300 surfaces before and after EP. The initial surface is cleaned with acetone, followed by the ultrasonic cleaner. EDS analysis of maraging steel before and after EP is shown in Fig. 5. EP is performed at $60^{\circ} \mathrm{C}$ with magnetic stirrer bar rotation at $400 \mathrm{rpm}$. Table 3 shows the changes in the surface's elemental compositions before and after EP, which is negligible [21]. However, the sub-surface composition is not measured with EDS. An increase in \% oxygen composition indicates that an oxide layer is formed on the surface after EP, increasing corrosion resistance [22]. EDS analysis suggests that after $\mathrm{EP}$, the concentration of $\mathrm{Ni}^{+}$increases, and $\mathrm{Fe}^{+}$decreases at the passive layer [23].

Table 3

Elemental composition of Maraging steel in wt.\%

\begin{tabular}{l|llllllllll|}
\hline & $\begin{array}{l}\text { Element } \\
\text { Process }\end{array}$ & Fe & Ni & Co & Mo & O & Ti & Al \\
$\qquad$\begin{tabular}{lllllllll} 
Before EP & 68.7 & 17.2 & 8.1 & 4.9 & 0.4 & 0.4 & 0.2 \\
\hline After EP & 66.8 & 18.2 & 8.4 & 4.8 & 1.1 & 0.5 & 0.2 \\
\hline
\end{tabular} \\
reflectance
\end{tabular}

During electropolishing, the temperature has a significant effect on the surface roughness. As the temperature increases, the conductivity of electrolytes increases, which increases the anodic dissolution [24]. Figure 6 shows the percentage improvement in the surface roughness with temperature. As temperature increases, the surface roughness decreases. A maximum gain of $55.47 \%$ is observed at 60 ${ }^{\circ} \mathrm{C}$. At higher temperatures, faster anodic dissolution occurs, which leads to pitting the surface. Hence, the surface finish deteriorates. It can be inferred from Fig. 6 that beyond $60^{\circ} \mathrm{C}$ temperature, the percentage improvement in surface roughness decreases.

The temperature has a significant effect on surface reflectance during EP. The surface reflectance at various temperatures is shown in Fig. 7. The relative surface reflectance is measured with reference to a highly polished silver surface having a $100 \%$ reflectivity. The magenta dot line shows the surface reflectance of the unpolished base material. The ultra-violet (UV) light is varied between 1000 to $200 \mathrm{~nm}$. 
It can be inferred from Fig. 7 that at $60^{\circ} \mathrm{C}$, surface reflectance is maximum (represented by the solid red line). At higher temperatures, pitting occurs, which decreases surface reflectance.

\subsection{Effect of agitation on surface roughness and surface reflectance}

The effect of agitation on surface roughness is shown in Fig. 8. A magnetic stirrer is used to provide agitation to the solution during EP. The magnetic bar is rotated from 0 to $600 \mathrm{rpm}$ to see its effect on workpiece surface roughness. Electropolishing was performed at $60^{\circ} \mathrm{C}$ for 6 minutes with a varied magnetic stirrer rotation between 0 to $600 \mathrm{rpm}$. It can be inferred from Fig. 8 that as the rotational speed increases from 0 to $400 \mathrm{rpm}$, surface roughness decreases during EP due to the stirring of the electrolyte and further easy removal of the gas bubbles. The maximum improvement in surface roughness is observed as $56.25 \%$ at 400 rpm magnetic bar rotation. With increased rotational speed from 400 to 600 rpm, the viscous layer formed on the anode surface becomes unstable, increasing surface roughness [25].

A comparison of surface reflectance between unpolished and electropolished samples at different rotations (between 0 to $600 \mathrm{rpm}$ ) of the magnetic stirrer is shown in Fig. 9. Electropolishing is performed at $60^{\circ} \mathrm{C}$ for 6 minutes. The magenta dot line shows the surface reflectance of the unpolished base material. The higher the surface finish, the higher will be the surface reflectance. It can be inferred from Fig. 9 that at $400 \mathrm{rpm}$, maximum reflectance of $60.3 \%$ is observed.

\subsection{Effect of polishing time on surface roughness and reflectance}

The percentage improvement of the surface roughness with polishing time is shown in Fig. 10. The polishing time is varied between 4 to 10 minutes at an interval of 2 minutes. It can be inferred from Fig. 10 that as polishing time increases, surface finish increases. However, with the rise in polishing time, the amount of material removal also increases. The maximum improvement of $56.16 \%$ in surface roughness is obtained at 6 minutes of EP (Fig. 10). For a longer duration of EP, the amount of anodic dissolution increases, and alloying elements starts leaving the surface, creating pits and deteriorating surface finish [26].

A comparison of surface reflectance of the electropolished sample with the unpolished one is represented in Fig. 11. Electropolishing is performed at $60^{\circ} \mathrm{C}$ at a magnetic stirrer rotation of $400 \mathrm{rpm}$ while varying the polishing time between 4 to 10 minutes. The maximum reflectance of $59.71 \%$ is observed for 6 minutes of electropolishing, as inferred from Fig. 11.

\subsection{Effect of EP on workpiece surface wettability}

From the present study, the best EP parameters are $60{ }^{\circ} \mathrm{C}$ temperature, $400 \mathrm{rpm}$ of magnetic stirrer rotation, and 6 minutes of polishing time, at which experimentation is performed for contact angle analysis. The contact angle is measured by dropping a $2 \mu \mathrm{L}$ water droplet on the workpiece surface 
before and after EP, as shown in Fig. 12. An angle of $111.2^{\circ}\left(>90^{\circ}\right)$ is formed on the surface before EP (Fig. 12(a)), which signifies that the surface is hydrophobic. An angle of $68.6^{\circ}\left(<90^{\circ}\right)$ is formed after EP (Fig. 12(b)), which signifies that the surface is hydrophilic. The electropolishing process changes the surface contact angle and makes it hydrophilic [25].

\subsection{Effect of EP on corrosion behavior}

The corrosion resistance of the maraging steel is an essential parameter for practical application. Potentiodynamic polarization curves measure the corrosion-resistance of maraging steel before and after EP with 3.5 wt.\% NaCl solution [20]. As shown in Fig. 13, a higher value of corrosion potential of maraging steel is observed after EP. However, corrosion current density of maraging steel decreases from $16.5 \mu \mathrm{A} / \mathrm{cm}^{2}$ to $6.84 \mu \mathrm{A} / \mathrm{cm}^{2}$ after EP (Table 4), indicating higher corrosion resistance of electropolished maraging steel. Higher $\mathrm{E}_{\text {corr }}$ and lower $\mathrm{I}_{\text {corr }}$ values increase corrosion resistance [22], [27].

Table 4

Potentiodynamic corrosion test result

\begin{tabular}{|lll|}
\hline Conditions & $\mathrm{E}_{\text {corr }}(\mathrm{V}$ vs. Ag/AgCl $)$ & $\mathrm{I}_{\text {corr }}\left(\mu \mathrm{A} / \mathrm{cm}^{2}\right)$ \\
\hline Before EP & -0.475 & 16.5 \\
\hline After EP & -0.397 & 6.84 \\
\hline
\end{tabular}

Surface reflectivity and corresponding 3D surface profile before and after EP are shown in Fig. 14. EP is performed at $6 \mathrm{~V}, 60^{\circ} \mathrm{C}$, and $400 \mathrm{rpm}$ for 6 minutes. It can be inferred from Figs. 14(a) and (b) that the surface reflectance improved significantly. Corresponding 3D surface profile is shown in Fig. 14(c) and (d) for the workpiece surface before and after EP respectively. To analyse the surface roughness $\left(R_{a}\right)$ profile before and after EP, both the profiles are drawn in the same graph as shown in Fig. 14(e). EP has reduced surface irregularities, and corresponding surface roughness $\left(R_{a}\right)$ of $0.272 \mu \mathrm{m}$ (Fig. 14(a)) is reduced to $0.119 \mu \mathrm{m}$ (Fig. 14(b)) by EP.

\section{Conclusions}

Electropolishing of maraging steel 300 is performed with acetic acid (99.7 wt.\%) and perchloric acid (70 wt.\%) mixed in a volume ratio of 3:1. Linear sweep voltammetry is conducted to determine the passive region in which the best EP performance can be achieved. EDS analysis is performed before and after EP to see the change in elemental composition. Effect of temperature, agitation, and polishing time on surface roughness and surface reflectance is observed before and after EP.

- EDS analysis shows that the nickel and oxygen concentrations on EP polished surface increase. It might form nickel oxide, which gives resistance to corrosion.

- Effect of temperature is studied to enhance the surface finish as well as surface reflectance. At 60 ${ }^{\circ} \mathrm{C}$, a maximum improvement of $55.47 \%$ in surface roughness is observed. Maximum surface reflectance is also observed at this temperature. Further increase in temperature makes the 
electrolyte more conductive, allowing the uncontrolled movement of ions, decreasing surface finish and reflectance.

- Agitation of electrolytes has significant importance in EP to enhance surface finish as well as surface reflectance. Rotation of magnetic stirrer at $400 \mathrm{rpm}$ provides maximum improvement of $56.25 \%$ in surface roughness, and surface reflectance is also maximum at this agitation. A higher rotation at $600 \mathrm{rpm}$ makes the viscous layer unstable, which deteriorates the surface finish and reflectance.

- Polishing time of 6 mins gives a maximum improvement of $56.16 \%$ in surface roughness and maximum surface reflectance. EP time higher than 8 minutes leads to the removal of alloying elements from the surface forming pits. Thus, it deteriorates the surface finish and reflectance.

- The contact angle is changed from $111.2^{\circ}$ to $68.6^{\circ}$ after EP. From contact angle analysis, it can be concluded that EP makes the surface hydrophilic, which can be used in anti-fogging applications, biomedical, filtration, heat pipes, etc.

- EP improves the corrosion resistance of the surface as $E_{\text {corr }}$ shifts from $-0.475 \mathrm{~V}$ to $-0.397 \mathrm{~V}$, and $\mathrm{I}_{\text {corr }}$ shifts from $16.5 \mu \mathrm{A} / \mathrm{cm}^{2}$ to $6.84 \mu \mathrm{A} / \mathrm{cm}^{2}$ after EP. A more positive $E_{\text {corr }}$ and lesser $I_{\text {corr }}$ signifies increased corrosion resistance.

\section{Declarations}

\section{Funding}

Not applicable

\section{Conflicts of interest/Competing interests}

The author(s) declare no potential conflicts of interest with respect to the research, authorship, and/or publication of this article.

\section{Availability of data and material}

There is no other associated data.

\section{Code availability}

Not applicable

\section{Ethics approval}

Not applicable

\section{Consent to participate}

Not applicable 


\section{Consent for publication}

Not applicable

\section{Authors' contributions}

Abhinav Kumar - Conceptualization, Methodology, Visualization, Writing original draft

Suraj kumar - Data collection, experimental investigation

Manas Das - Conceptualization, Resources, Reviewing, and Editing

\section{Acknowledgment}

The authors acknowledge the Department of Physics of Indian Institute of Technology Guwahati, Assam, India, for providing a UV spectrometer for surface reflectance analysis.

\section{References}

1. Jacquet PA (1936) The mechanism of electrolytic polishing of Copper. CR Acad Sci 202:402

2. Lee SJ, Lai JJ, "The effects of electropolishing (EP) process parameters on corrosion resistance of 316 L stainless steel," J. Mater. Process. Technol., vol. 140, no. 1-3, pp. 206-210, Sep. 2003, doi: 10.1016/S0924-0136(03)00785-4

3. Bala Srinivasan P, Marikkannu C, Ramu S, Balakrishnan K (1994) Corrosion of maraging steels in chloride solutions. Br Corros J 29(2):132-135. doi:10.1179/000705994798267782

4. Lee ES (2000) Machining characteristics of the electropolishing of stainless steel (STS316L). Int J Adv Manuf Technol 16(8):591-599. doi:10.1007/s001700070049

5. Han W, Fang F, "Fundamental aspects and recent developments in electropolishing," Int. J. Mach. Tools Manuf., vol. 139, no. April, pp. 1-23, 2019, doi: 10.1016/j.ijmachtools.2019.01.001

6. Poornima T, Nayak J, Nityananda Shetty A, “Effect of 4-(N,N-diethylamino)benzaldehyde thiosemicarbazone on the corrosion of aged $18 \mathrm{Ni} 250$ grade maraging steel in phosphoric acid solution," Corros. Sci., vol. 53, no. 11, pp. 3688-3696, Nov. 2011, doi: 10.1016/j.corsci.2011.07.014

7. Ansell TY, Ricks JP, Park C, Tipper CS, Luhrs CC (2020) Mechanical Properties of 3D-Printed Maraging Steel Induced by Environmental Exposure. Metals (Basel) 10(2):218. doi:10.3390/met10020218

8. Oliveira AR, Jardini AL, Del Conte EG, "Effects of cutting parameters on roughness and residual stress of maraging steel specimens produced by additive manufacturing," Int. J. Adv. Manuf. Technol., vol. 111, no. 9-10, pp. 2449-2459, Dec. 2020, doi: 10.1007/s00170-020-06309-3

9. Li B, Ding Z, Xiao J, Liang SY, "Maraging steel 3J33 phase transformation during micro-grinding," Mater. Lett., vol. 164, pp. 217-220, Nov. 2015, doi: 10.1016/j.matlet.2015.10.162 
10. Huang $\mathrm{CA}$, Chen $\mathrm{YC}$, Chang JH, "The electrochemical polishing behavior of the Inconel 718 alloy in perchloric-acetic mixed acids," Corros. Sci., vol. 50, no. 2, pp. 480-489, Feb. 2008, doi: 10.1016/j.corsci.2007.07.005

11. Huang CA, Chen YC (2009) The effect of water content on the electropolishing behavior of Inconel 718 alloy in perchloric-acetic acid mixtures. Corros Sci 51(9):1901-1906. doi:10.1016/j.corsci.2009.03.039

12. Aksu Y, Erdoğan M, Demirci G, Karakaya I (2016) Electropolishing of an Fe-Ni-Co Alloy in Acetic AcidPerchloric Acid Mixture. ECS Trans 72(22):13. doi:10.1149/07222.0013ecst

13. Wang G, Liu Z, Niu J, Huang W, Wang B (Jan. 2020) Effect of electrochemical polishing on surface quality of nickel-titanium shape memory alloy after milling. J Mater Res Technol 9(1):253-262. doi:10.1016/j.jmrt.2019.10.053

14. Han W, Fang F, "Eco-friendly NaCl-based electrolyte for electropolishing 316L stainless steel," J. Manuf. Process., vol. 58, no. October, pp. 1257-1269, 2020, doi: 10.1016/j.jmapro.2020.09.036

15. Wang K, Yan Y, Zhou P, Zhang C, Kang R, Guo D, "Preparation of Flat and Smooth Copper Surface by Jet Electrochemical Machining and Electrochemical Polishing," J. Electrochem. Soc., vol. 167, no. 16, p. 163501 , Nov. 2020, doi: $10.1149 / 1945-7111 /$ abcbb2

16. Piotrowski D, $O$ and Madore C, Landolt (1998) The mechanism of electropolishing of titanium in methanol-sulfuric acid electrolytes. J Electrochem Soc 145(7):2362

17. Zhao T, Wang S, Liu Z, Du C, Li X (Feb. 2021) Effect of cathodic polarisation on stress corrosion cracking behaviour of a $\mathrm{Ni}(\mathrm{Fe}, \mathrm{Al})$-maraging steel in artificial seawater. Corros Sci 179:109176. doi:10.1016/j.corsci.2020.109176

18. Barman A, Das M (Jan. 2018) Nano-finishing of bio-titanium alloy to generate different surface morphologies by changing magnetorheological polishing fluid compositions. Precis Eng 51:145-152

19. Rudawska A, Jacniacka $E$ (Apr. 2018) Evaluating uncertainty of surface free energy measurement by the van Oss-Chaudhury-Good method. Int J Adhes Adhes 82:139-145.

doi:10.1016/j.ijadhadh.2018.01.006

20. Hou Y, Li R, Liang J, Su P, Ju P (Feb. 2018) Electropolishing of Al and Al alloys in AICl3/trimethylamine hydrochloride ionic liquid. Surf Coatings Technol 335:72-79. doi:10.1016/J.SURFCOAT.2017.12.028

21. Tyagi F, Pawan and Goulet, Tobias and Brent, Denikka and Klein, Kate and Garcia-Moreno, "Scanning Electron Microscopy and Optical Profilometry of Electropolished Additively Manufactured 316 Steel Components," in ASME International Mechanical Engineering Congress and Exposition, no. 52019, 2018, p. V002T02A019

22. Han W, Fang F, "Electropolishing of 316L stainless steel using sulfuric acid-free electrolyte," J Manuf Sci Eng, 141, 10, 2019, doi:10.1115/1.4044518

23. Haidopoulos M, Turgeon S, Sarra-Bournet C, Laroche G, Mantovani D (2006) Development of an optimized electrochemical process for subsequent coating of 316 stainless steel for stent applications. J Mater Sci Mater Med 17(7):647-657 
24. Kumar A, Das M (2021) Multiphysics simulation and experimental investigation of microtool fabricated by EMM. Mater Manuf Process 36(13):1489-1500. doi:10.1080/10426914.2021.1905837

25. Tyagi $P$ et al (Feb. 2020) Roughness Reduction of Additively Manufactured Steel by Electropolishing. Int J Adv Manuf Technol 106:no. 3-4. doi:10.1007/s00170-019-04720-z., “, , , , pp. 1337-1344

26. Habibzadeh S, Li L, Shum-Tim D, Davis EC, Omanovic S (Oct. 2014) Electrochemical polishing as a $316 \mathrm{~L}$ stainless steel surface treatment method: Towards the improvement of biocompatibility. Corros Sci 87:89-100. doi:10.1016/j.corsci.2014.06.010

27. Pal A, Das C (Sep. 2020) A novel use of solid waste extract from tea factory as corrosion inhibitor in acidic media on boiler quality steel. Ind Crops Prod 151:112468. doi:10.1016/j.indcrop.2020.112468

\section{Figures}




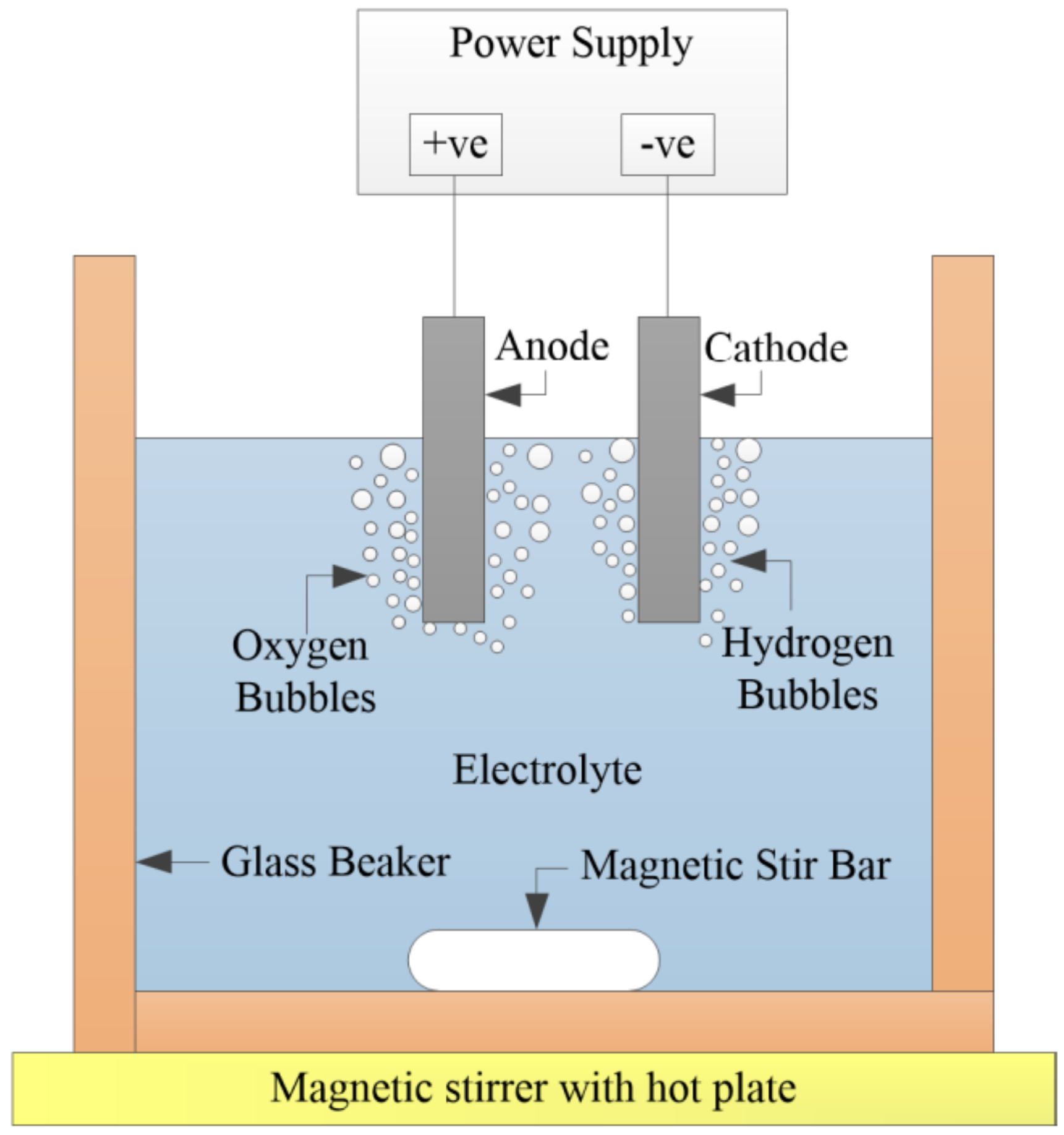

Figure 1

Schematic of electropolishing setup

空

Figure 2

Experimental setup for EP 


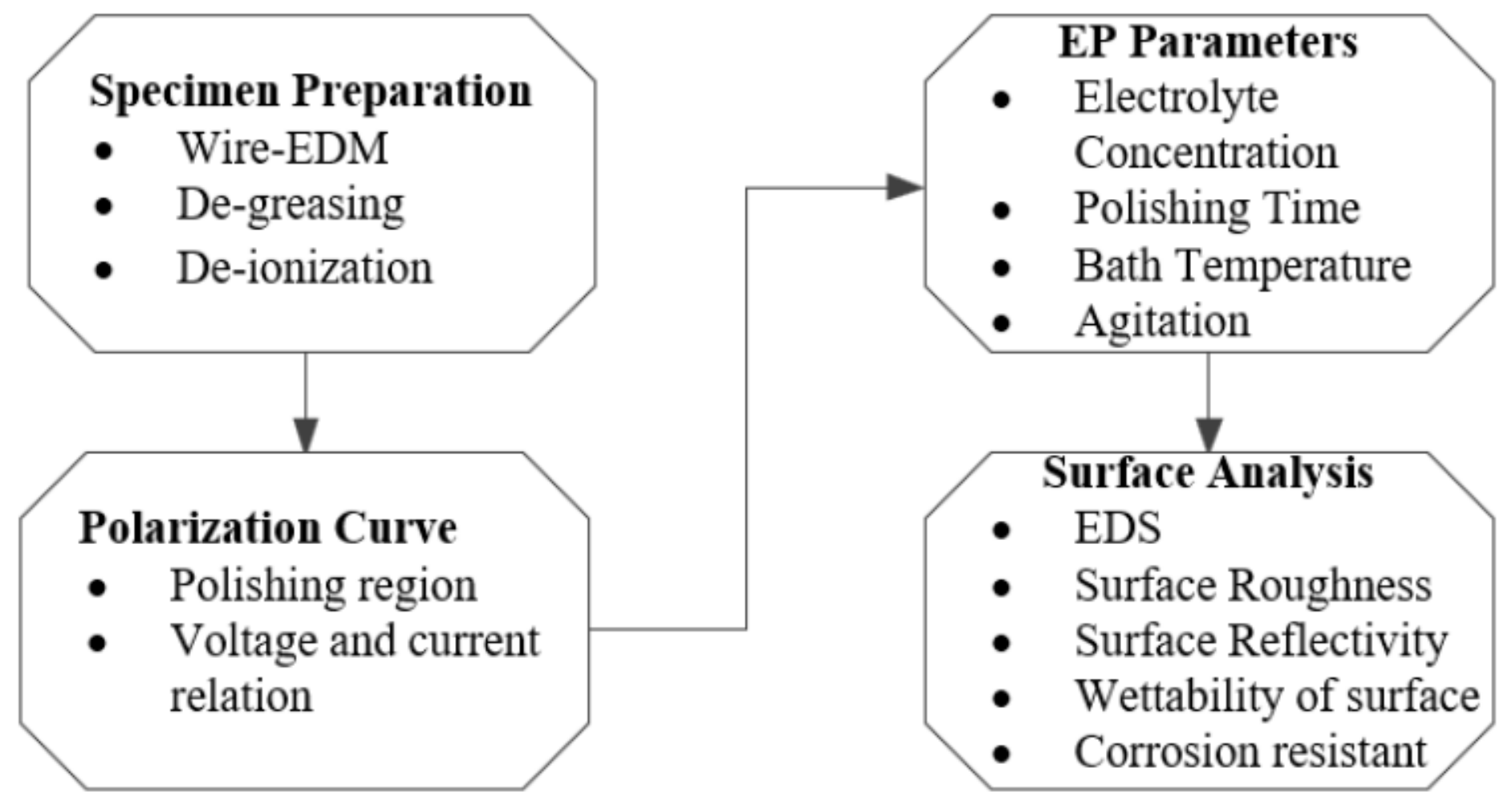

Figure 3

Flow chart of electropolishing process 


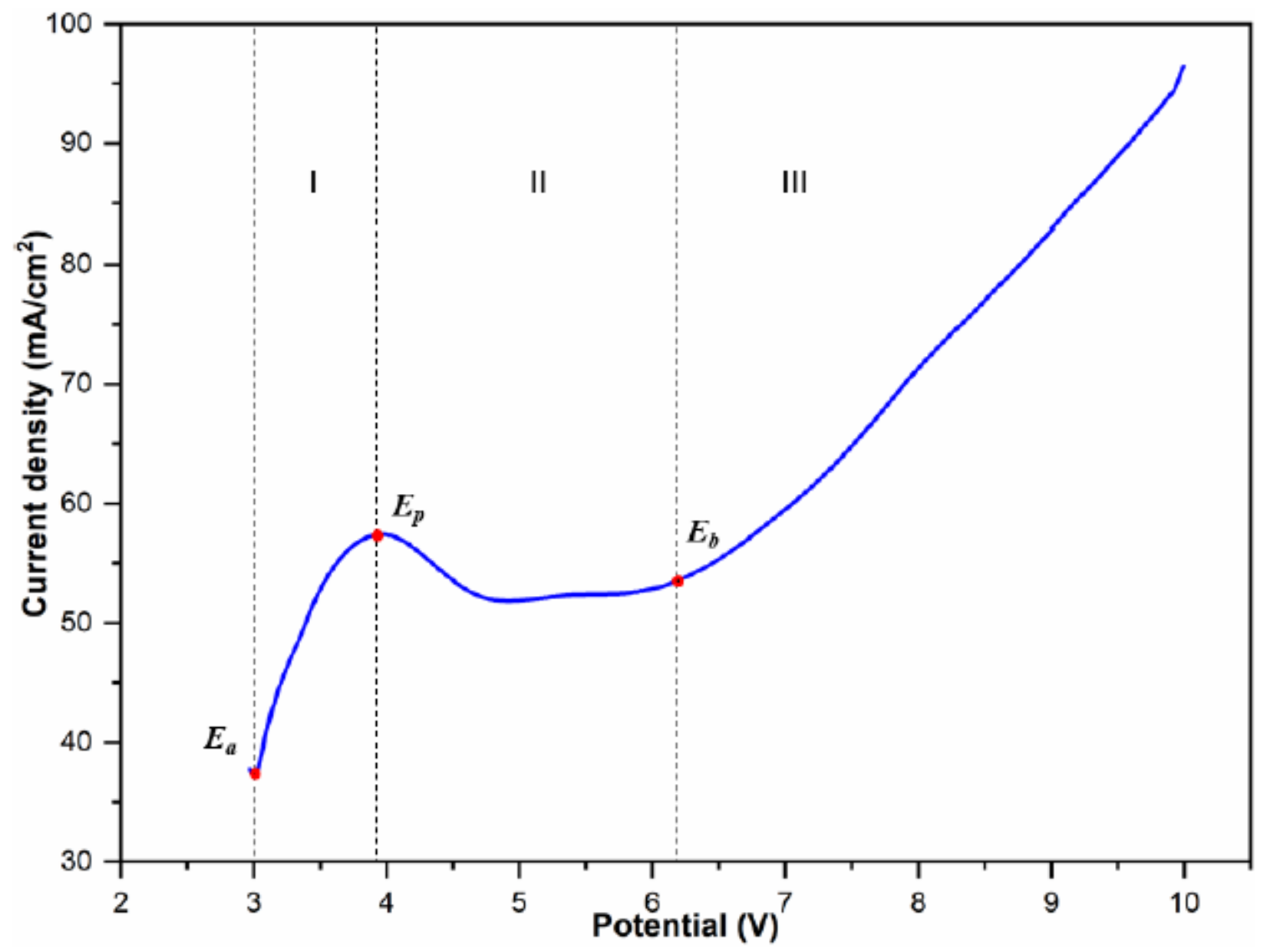

Figure 4

Anodic polarization behavior of maraging steel

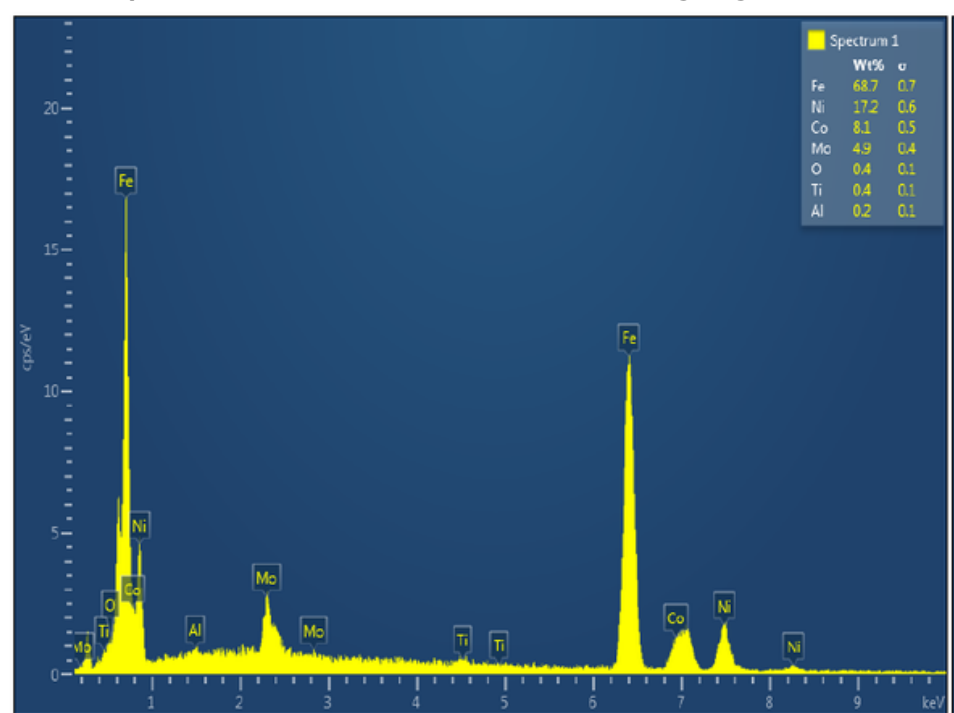

(a)

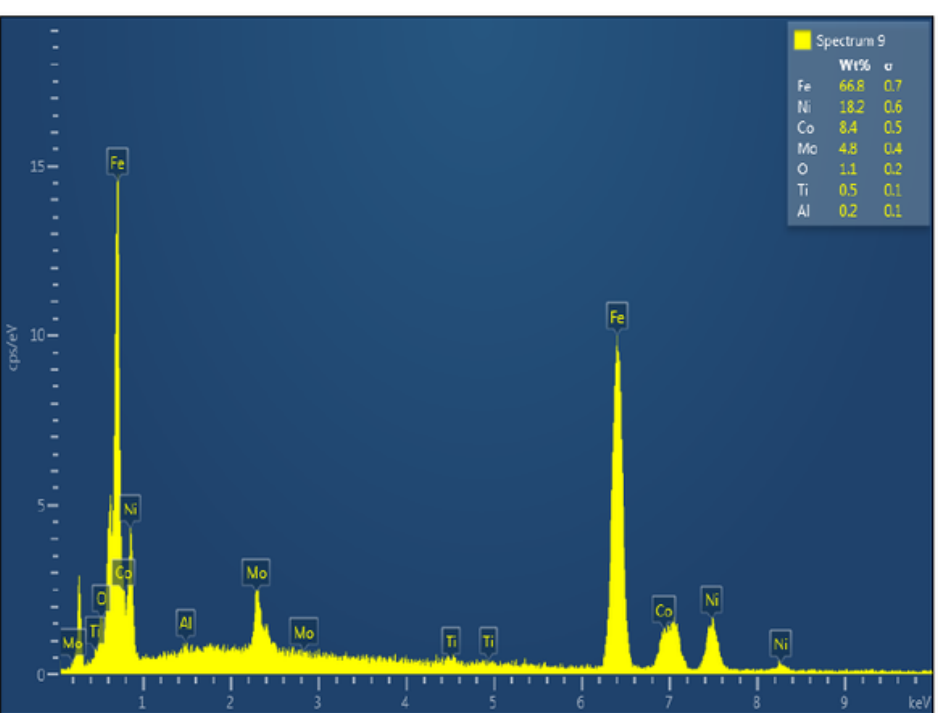

(b)

Figure 5

EDS analysis of maraging steel 300 (a) before EP and (b) after EP 


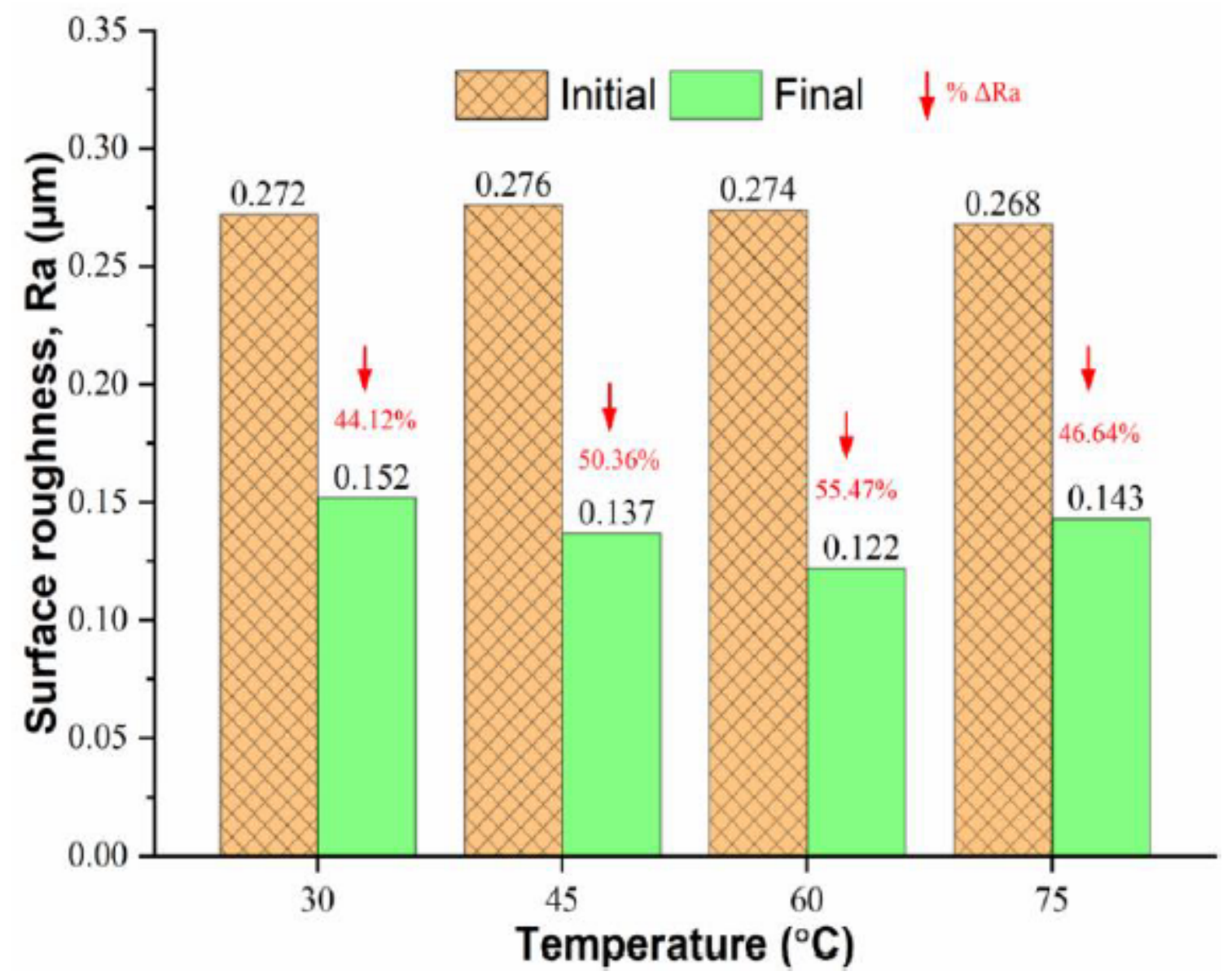

Figure 6

Effect of temperature on surface roughness after EP with \% improvement 


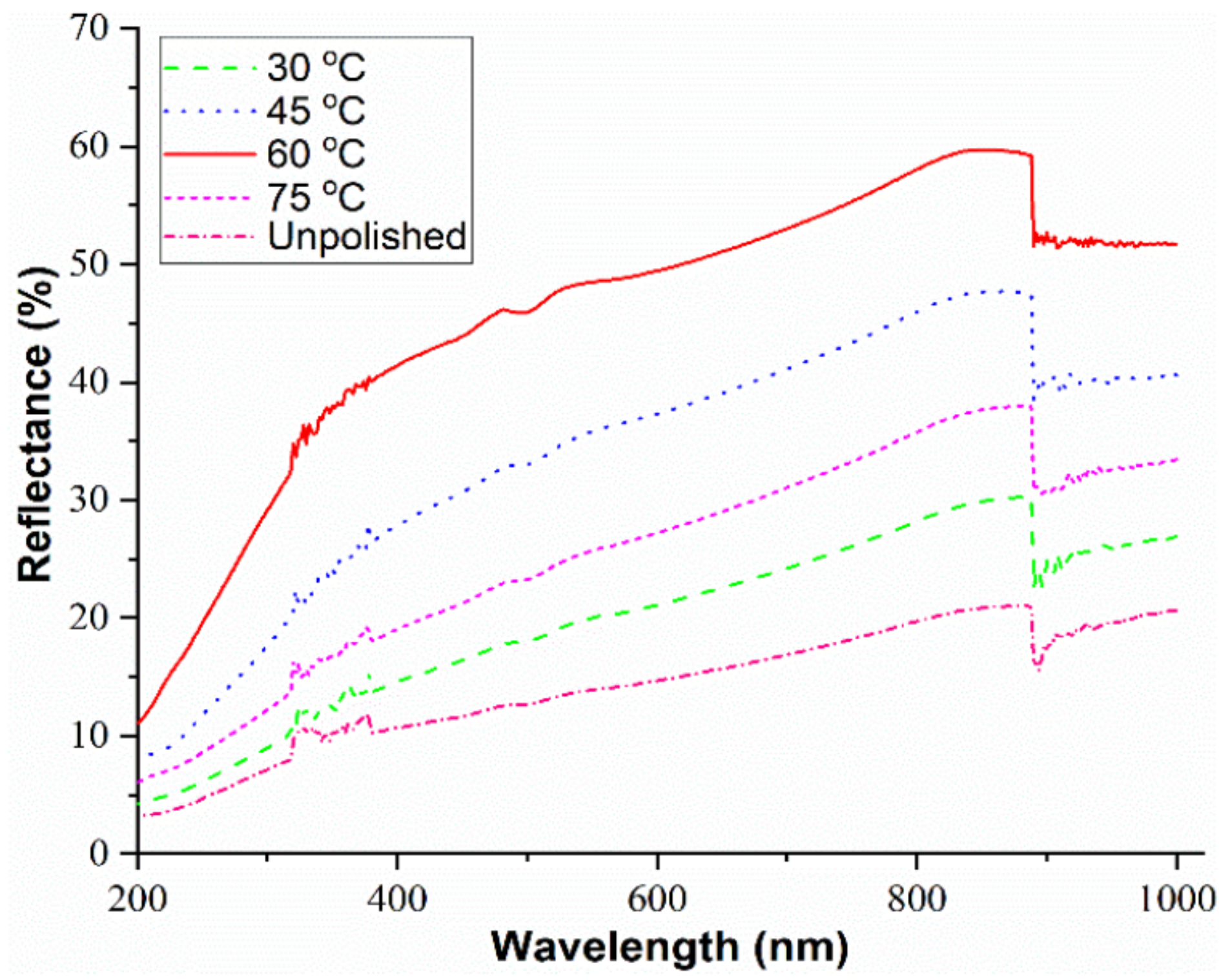

Figure 7

Effect of temperature on surface reflectance 


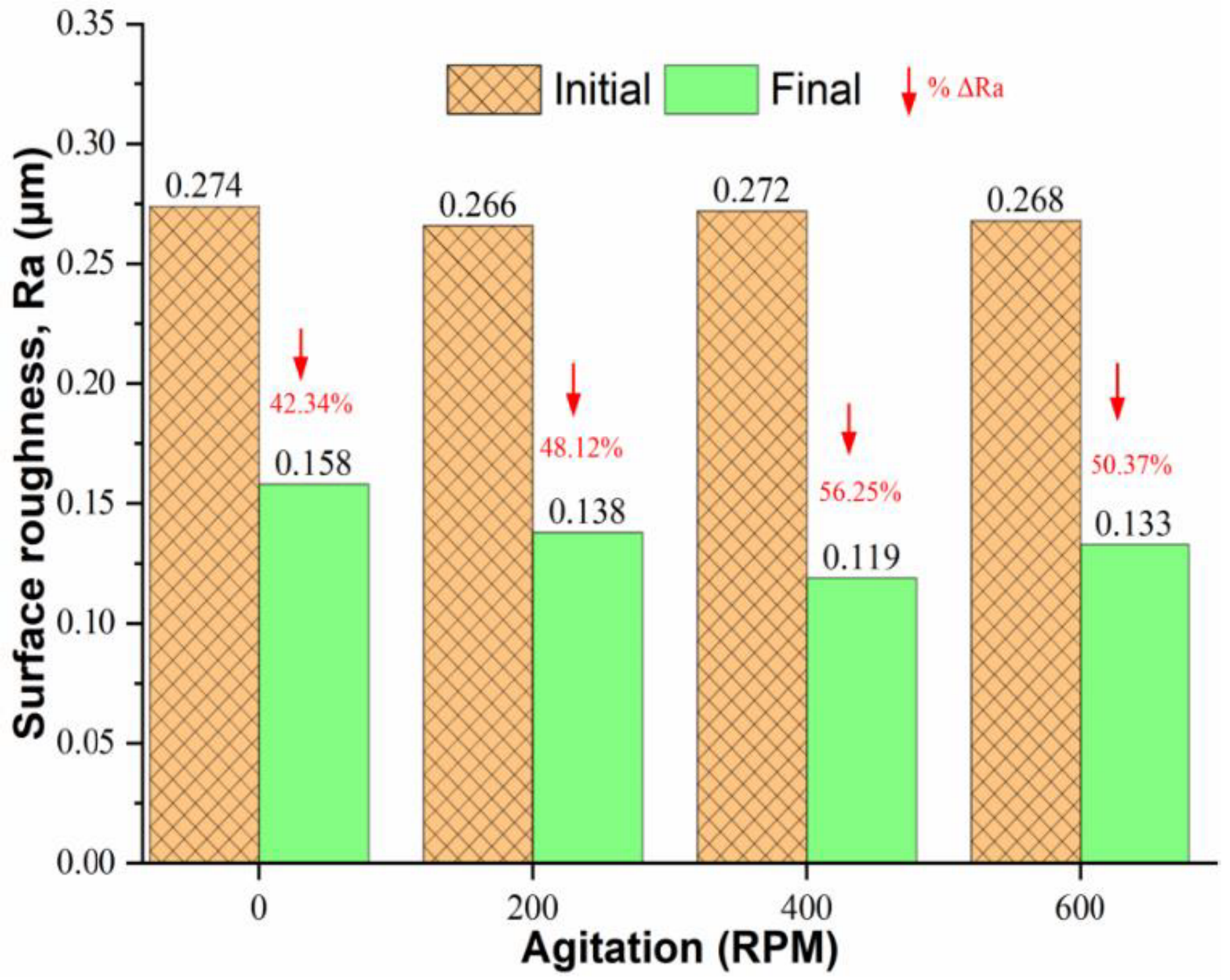

Figure 8

Effect of magnetic stirrer agitation on surface roughness 


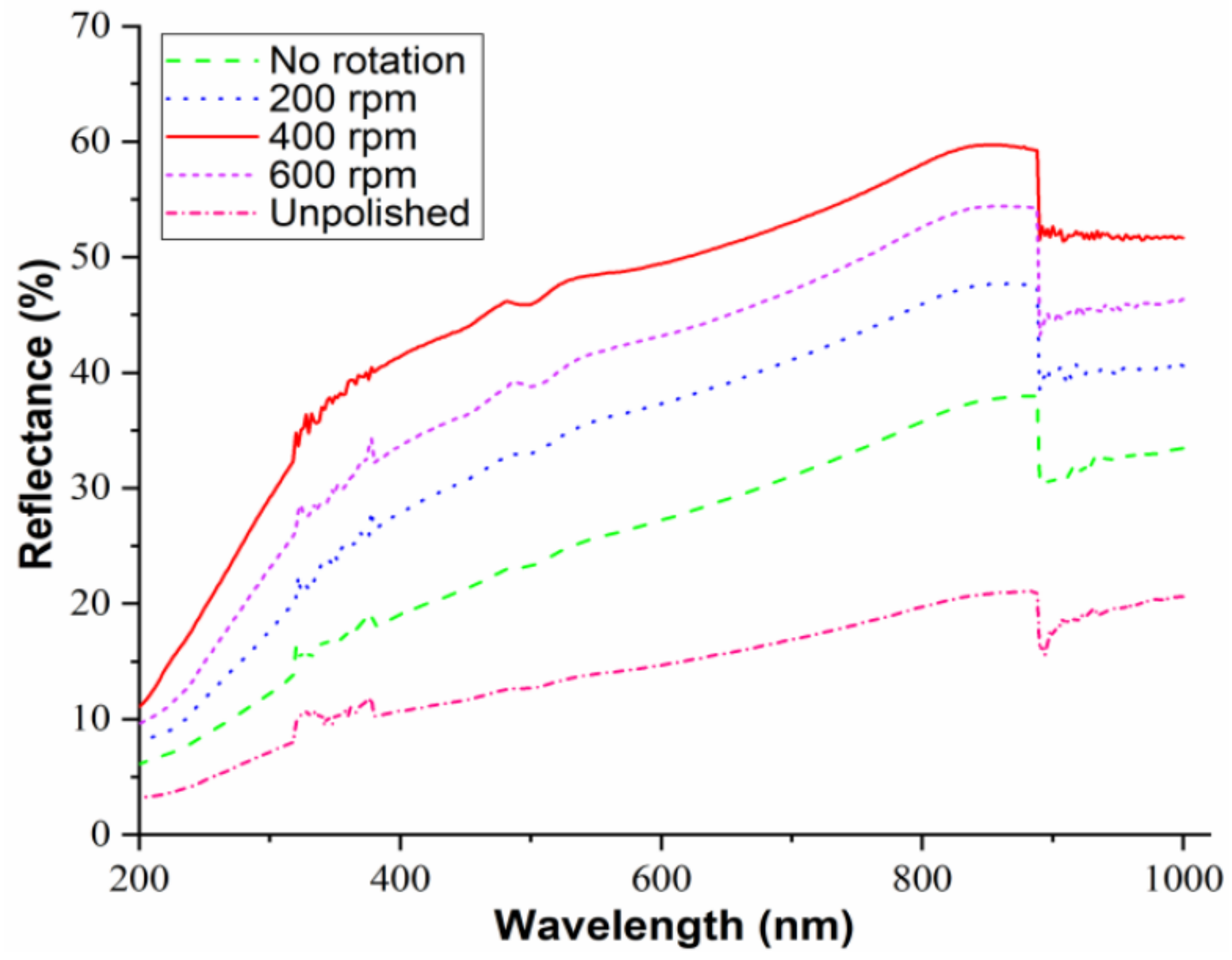

Figure 9

Effect of agitation on surface reflectance 


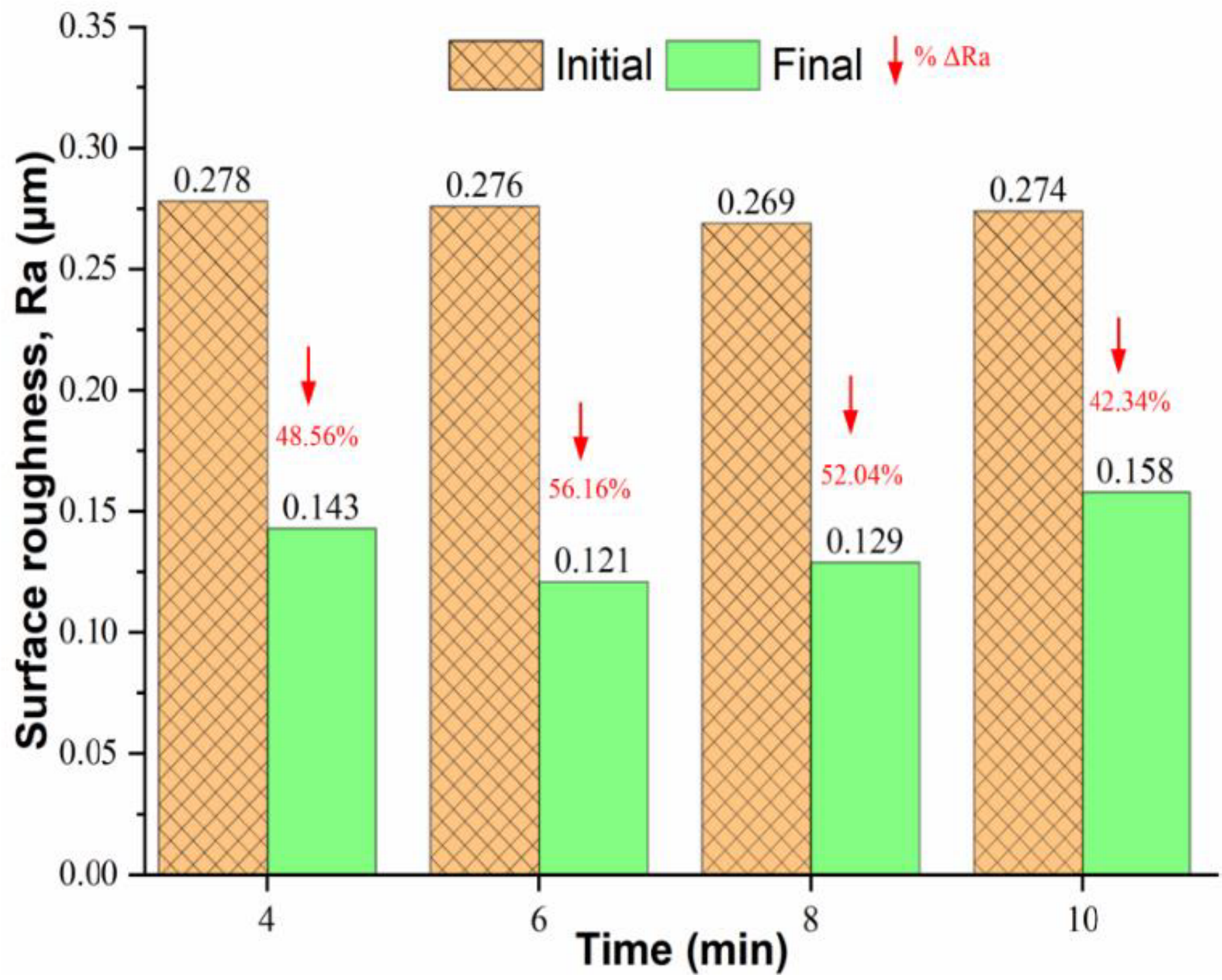

Figure 10

Effect of polishing time on surface roughness 


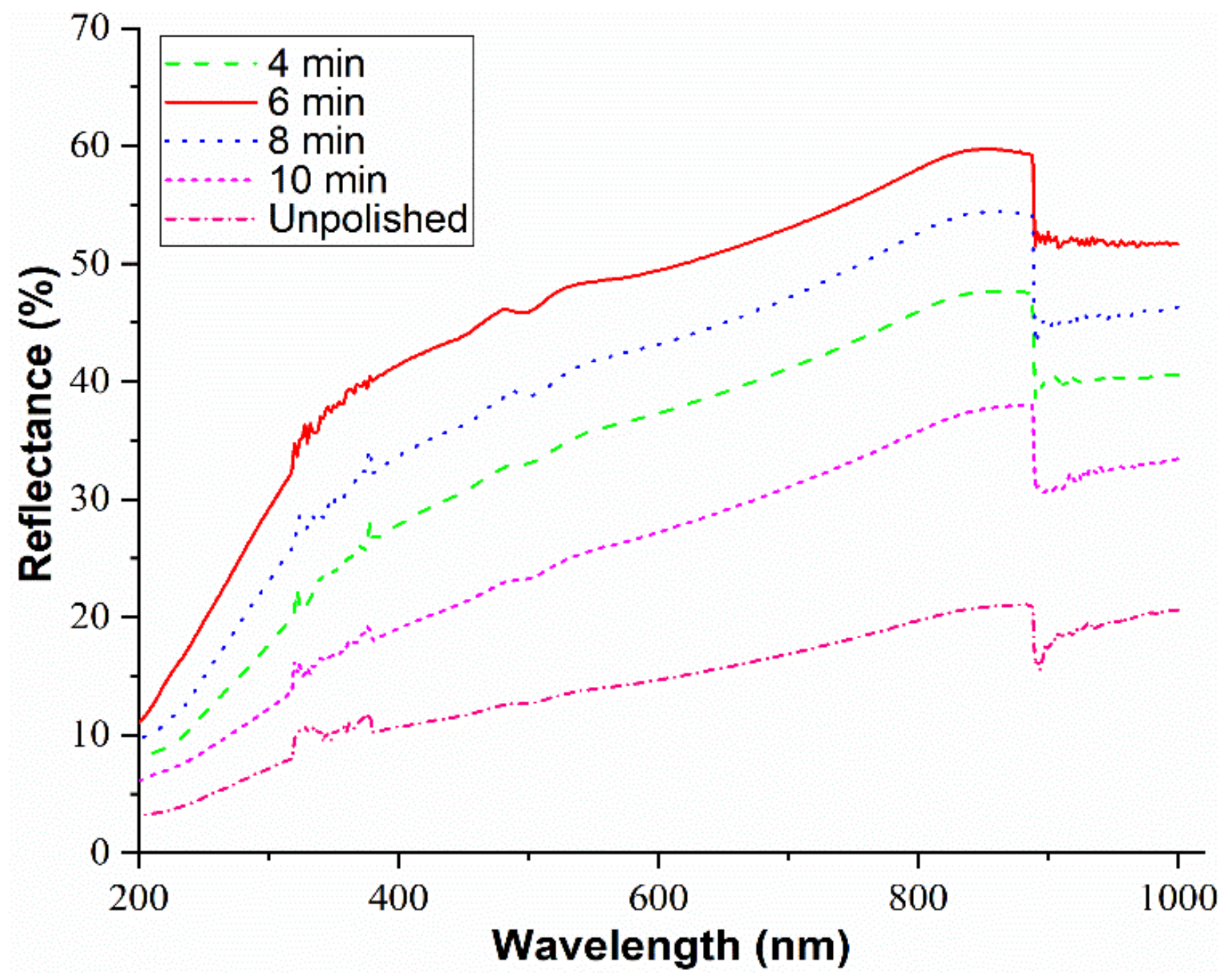

Figure 11

Effect of polishing time on surface reflectance 


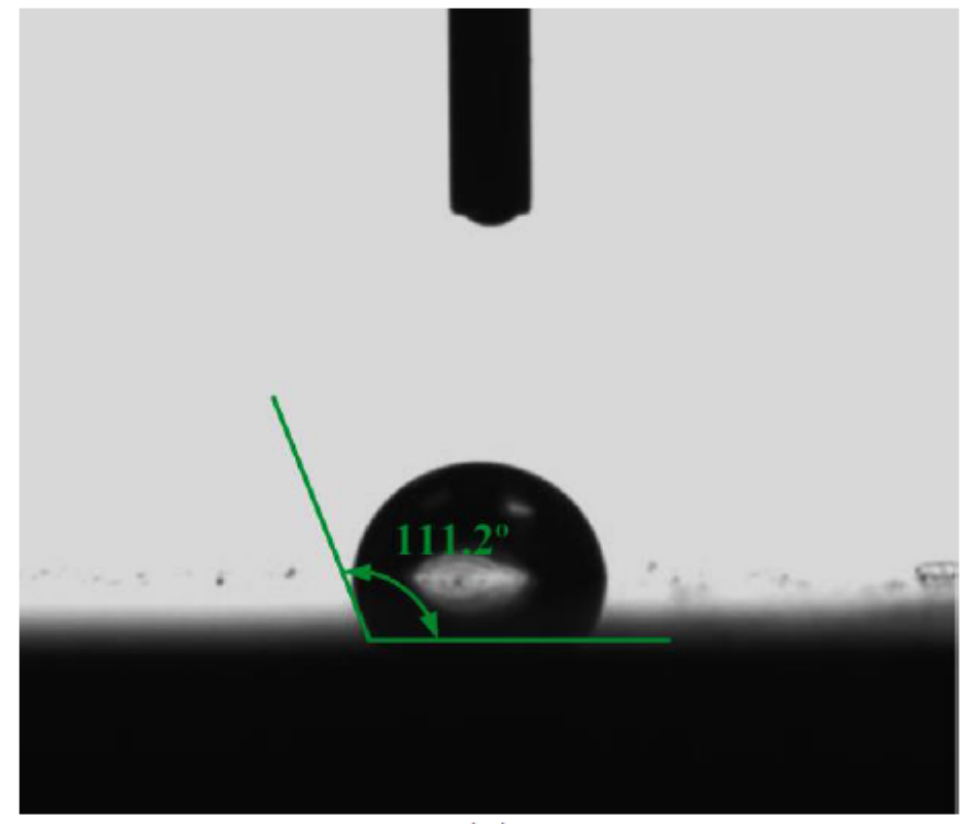

(a)

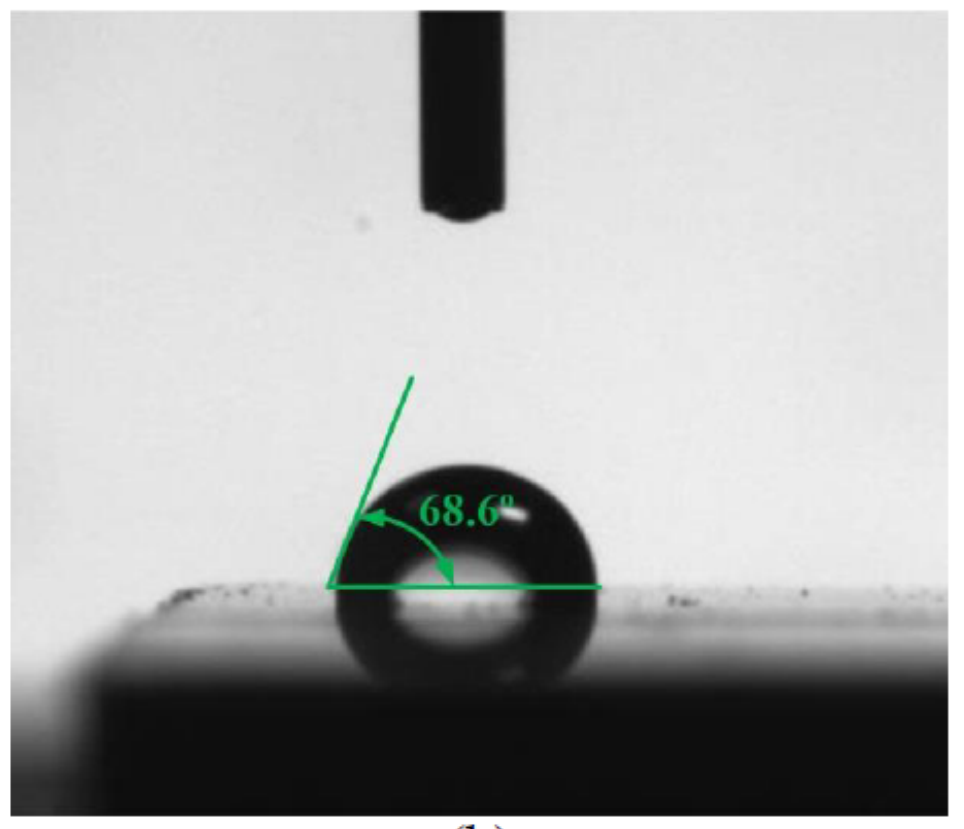

(b)

Figure 12

Contact angles (a) before and (b) after EP

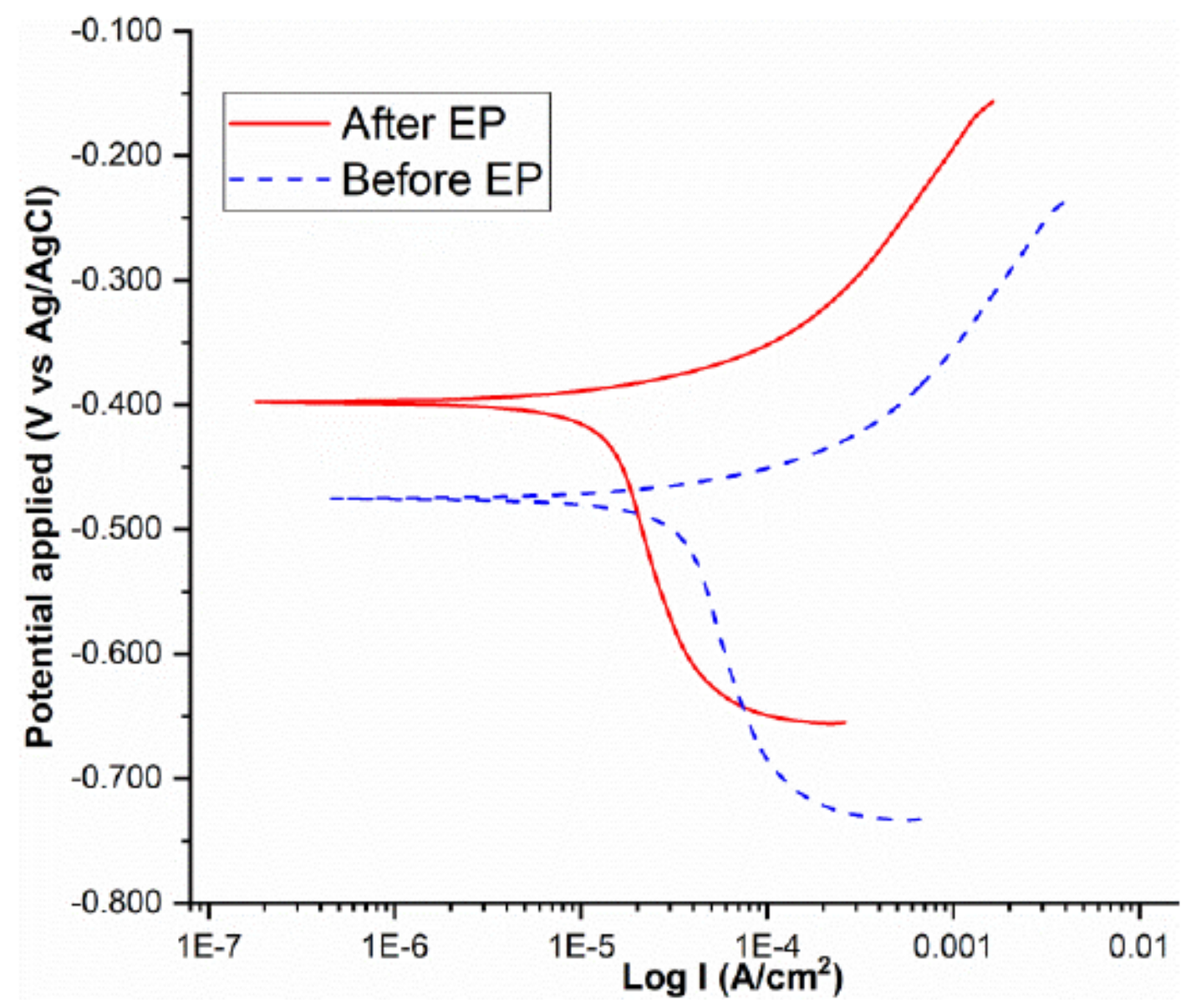

Figure 13 
Tafel polarization curve before and after EP

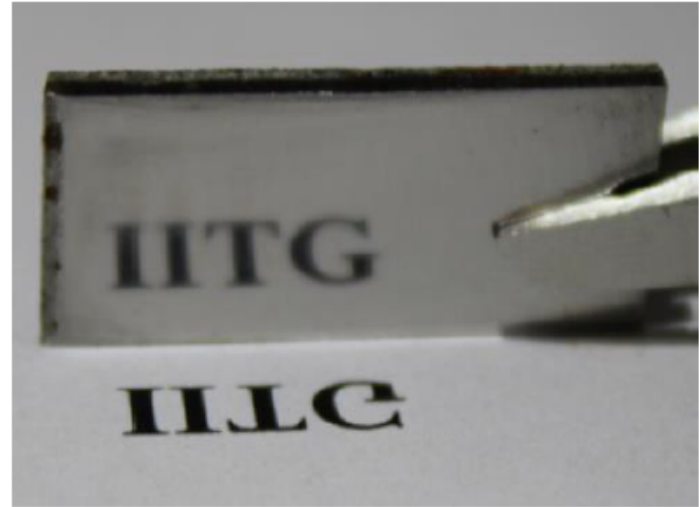

(a)

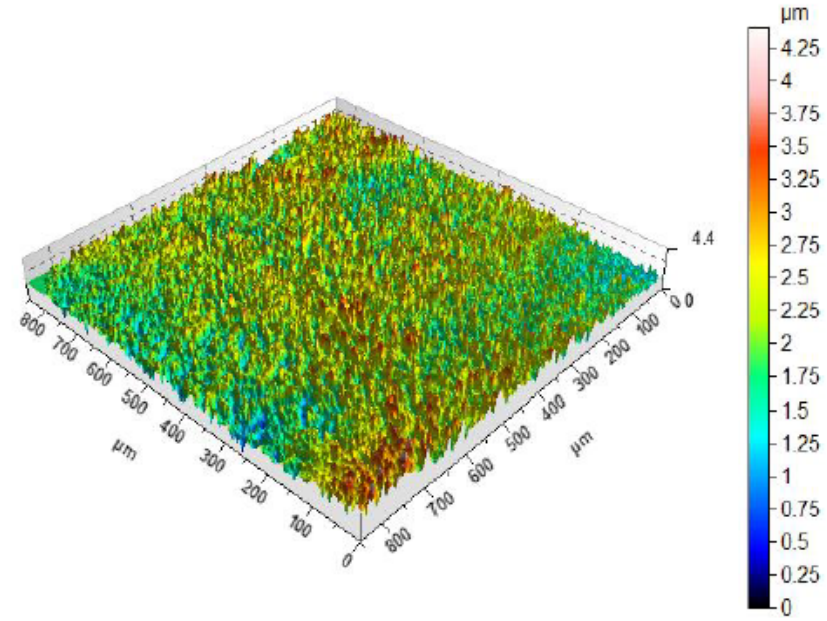

(c)

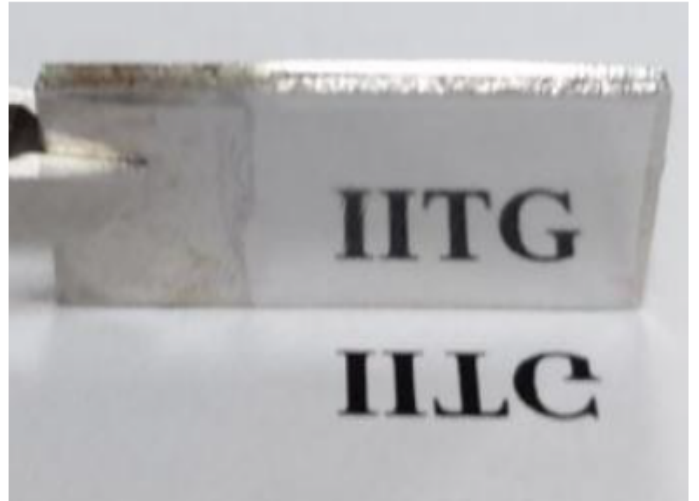

(b)

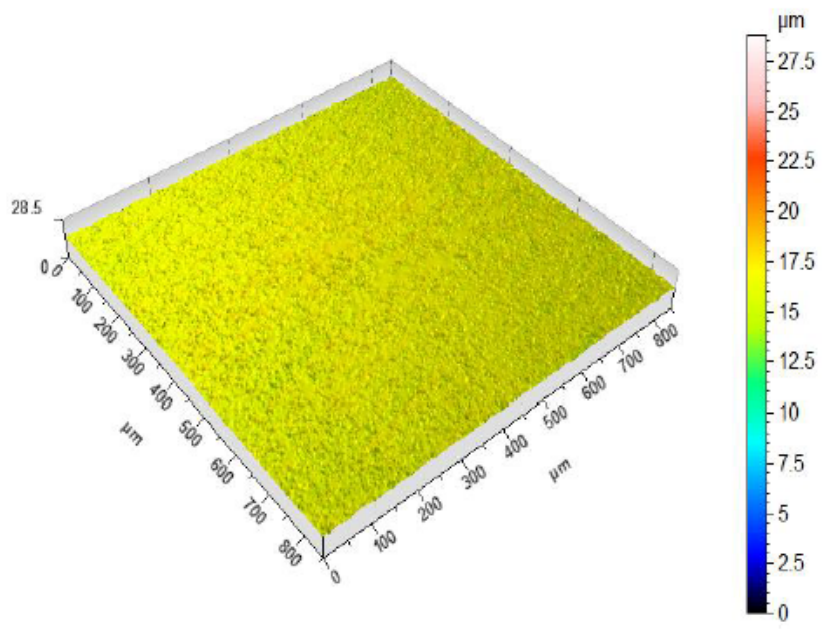

(d)

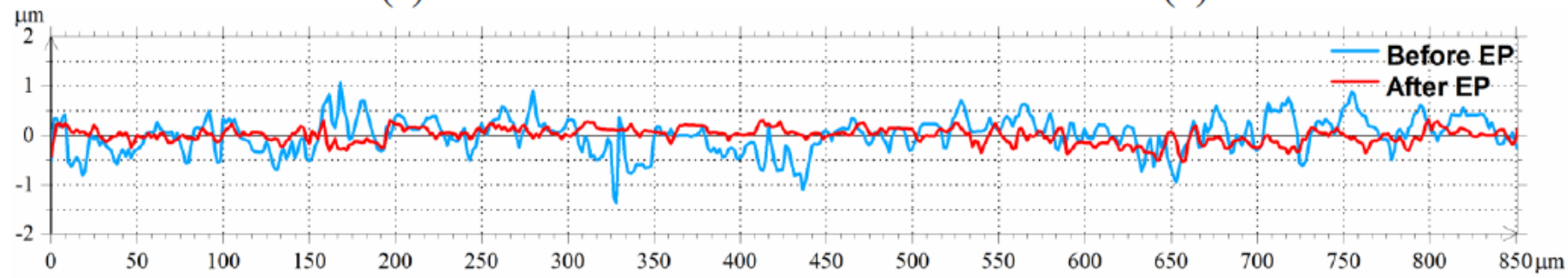

(e)

Figure 14

Surface reflectance (a) before and (b) after EP; 3D surface roughness profile (c) before and (d) after EP; (e) 2D surface roughness profile before and after EP 